\title{
ASSESSING VULNERABILITIES AS A STEP TOWARD CLIMATE CHANGE INDUCED HAZARD PREPAREDNESS
}

\author{
HARDY PUNDT, ANDREA HEILMANN \& MARTIN SCHEINERT \\ Harz University of Applied Sciences, Wernigerode, Germany.
}

\begin{abstract}
Increasingly, the consequences of climate change are recognized not only on a national, but also on the regional and local levels. More and more local administrations ask if and which measures should be implemented to be prepared concerning climate change induced hazards, such as flooding, soil erosion, or drought and heat periods in rural and/or urban environments.

Within the framework of a project carried out between 2013 and 2016, a local climate change adaptation strategy has been developed in a pilot region in middle Europe. Taking into account as many stakeholders, or actors from different sectors as possible, measures to adapt to climate change were defined based on the previous assessment of specific vulnerabilities. However, vulnerability assessment has been supported by the analysis of vast amount of spatial datasets using online geographic information services that were implemented as part of the project. Based on such technologies, as well as a web-based open forum, actors and the public were enabled to participate actively in the vulnerability assessment and especially concerning the definition of climate change adaptation measures. The participation process under explicit consideration of diverse relevant actors has lead to improved acceptance, and therefore more sustainable decisions about measures.

The benefits resulting from using open participation tools, including geographic information technologies and communication support, to identify and evaluate vulnerabilities will be discussed. This is linked to the goals of a follow-up project that starts in 2017, called 'BebeR', in which a special focus is on soil erosion due to increasing heavy rainfall events accompanied by flooding. The computer based support during the prioritization and implementation of measures to mitigate potential threats will be considered and conclusions be drawn.
\end{abstract}

Keywords: climate change adaptation, GIS, hazard preparedness, participation, vulnerability.

\section{INTRODUCTION}

Soil is an important natural resource. The erosion of soil consequently leads to a severe loss of this resource, thus having consequences for the economic prosperity of regions, as well as for natural sustainability. Besides that, soil erosion can lead to the destruction of infrastructures and hazardous situations for people. Within the framework of the project 'BebeR', the development of an adapted methodology to assess soil erosion and the consequences of adaptation measures is envisaged. The methodology will be tested and improved by different concerned parties.

The development, assessment and implementation of measures to minimize the erosion of soils require different steps, among others the identification of areas that are vulnerable to soil erosion. Soil erosion can be divided into surface erosion and riverbed erosion and caused either by wind or by water. To achieve a solid assessment of vulnerability, different methods and tools are needed that lead to reliable results on which future measures can be grounded. Until recently, the assessment of soil erosion risks on regional and national scales has been done based on the application of empirical models like the Universal Soil Loss Equation (USLE) and the Revised Universal Soil Loss Equation (RUSLE), often in combination with remote sensing and geographic information systems (GIS) [1]. However, the estimation of the potential loss of soil is only one aspect within a more complex framework that is needed to (a) identify vulnerabilities, (b) define measures, based on the vulnerability assessment and 
(c) evaluate whether such measures are effective. To achieve usable results in the areas (a) to (c), the integration of different methods and tools is necessary. Within the project 'KlimpassAktiv' (2013-2016) a methodology has been developed that enables local and regional authorities to generate specific, tailored to their needs, vulnerability maps as a prerequisite for the definition of measures to mitigate potential consequences of climate change. The methodology for the development of such maps considers vulnerability assessment as a process of continuous improvement. The methodology builds a basis for the project 'BebeR' that is aimed at the adaptation of existing, and the development of modified or new approaches that explicitly take into account experiences as well as expectations of all relevant actors from different concerned sectors like public authorities, agriculture, nature protection and water management. Therefore, the goal of 'BebeR' is to demonstrate, how planning processes aiming at the minimization of soil erosion can be optimized under consideration of requirements resulting from climate change. The project is focusing on rural, mountainous areas in which soil erosion can be a severe problem due to high gradients and slopes. The main envisaged result of the project, a practical and sustainable methodology to reduce soil erosion in view of future climate change induced weather events, should be transferable to other regions, thus making 'BebeR' a pilot project in this field of research and development.

\section{VULNERABILITY ASSESSMENT}

\subsection{Methodology of vulnerability assessment}

Vulnerability assessment is a complex task and requires the analysis of at least three factors: sensitivity, exposure and adaptive capacity, as shown in Figure 1. Whereas the sensitivity analysis requires insight into the environmental and socio-economic characteristics in a affected region, the exposure deals with the current and projected climate data in the region and its river catchments. Climate data are provided by simulation models such as WETTREG, REMO or STAR [2]. Using GIS, the layers (climate as well as socio-economic data) can be integrated easily aiming at making transparent statements about the situation of a region. The adaptive capacity, however, deals with the local and regional possibilities to

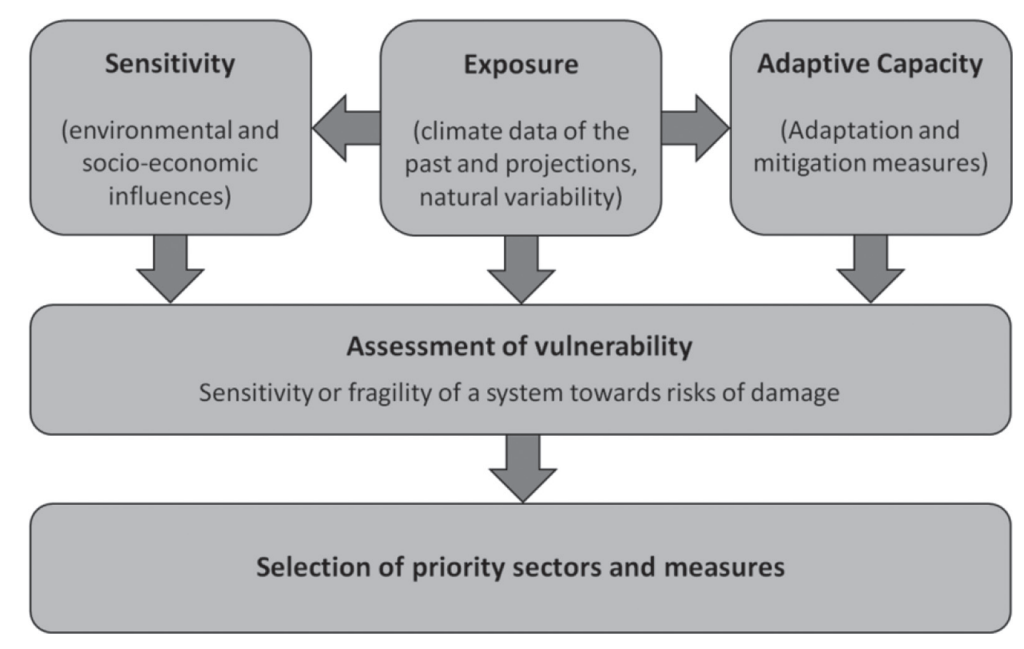

Figure 1: Determination of vulnerable areas (Source: [3], p. 10, modified). 


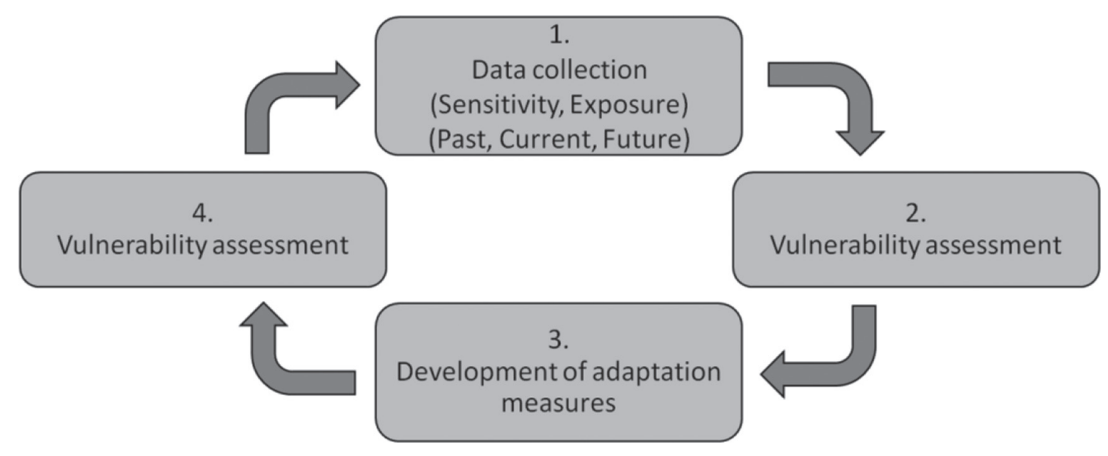

Figure 2: Step-by-step approach for vulnerability assessment.

implement adaptation measures concerning specific factors, in this case soil erosion. Different perspectives and experiences of the concerned actors have to be considered. The assessment of vulnerability, carried out under consideration of these three elements (sensitivity, exposure and adaptive capacity), leads to a solid grounding for the identification of the sectors that are prone to take action, and the definition of concrete measures to be implemented in the future in order to be prepared in case of hazardous situations.

A step-by-step procedure to determine vulnerability is presented in Figure 2. During data collection (step 1) the available data are compiled. Sensitivity and exposure are closely related. By using simulation models the effect of both, climate data as well as land use, agricultural technologies and/or new artificial elements (like storm water sewer) on soil erosion can be analysed. For the purpose of testing and model calibration, historical data are used. This will also lead to first assumptions concerning vulnerabilities (step 2). In order to assess the influence of adaptation measures (for instance on soil erosion), these have to be determined at first. The development of adaptation measures needs indispensably cooperation and cross-sector networking (step 3). The measures influence the adaptation capacity and finally the vulnerability assessment (step 4). Since data describing sensitivity as well as exposure have to be updated periodically and adaptation capacity is changing depending on planned measures it is essentially visible that vulnerability assessment is a process of continuous improvement.

\subsection{Assessment of soil erosion vulnerability}

When soil erosion is in the focus of vulnerability assessment, the RUSLE (Revised Universal Soil Loss Equation) is often used to predict the potential loss of soil [4]. The equation is based on the Universal Soil Loss Equation (USLE); however, the RUSLE model is a more adequate approach within the framework of the case study, which is presented in section 3. USLE enables users to predict soil erosion with acceptable accuracy [5], whereas RUSLE is more accurate in forecasting soil erosion. It is an evolution of the USLE equation, as it considers upstream areas contributing to downstream surface runoff. Thus, it is a model with better predictive ability. To assess the vulnerability of soils concerning erosion in river basins the RUSLE has been used many times and the usage of GIS to support vulnerability assessment has been documented in diverse publications (e.g. see Refs. [6-10]).

Within the framework of the above mentioned project 'Klimpass-Aktiv' vulnerability assessment has been carried out initially on a qualitative basis. The usage of different spatial 
Table 1: Data sets required for the assessment of soil vulnerability.

\begin{tabular}{ll} 
Data category & Examples \\
\hline Exposure & - Parameters measured during weather stations in the past (e.g. air tem- \\
& perature, precipitation totals and sunshine duration) \\
& - regional averages of these parameters \\
& - Predictions on a regional level using different models and scenarios \\
& - other observations (e.g. phenological data) \\
Sensitivity & - population and population development \\
& - stream network \\
& - land use (e.g. agriculture, forestry, infrastructure) \\
& - applied technologies (e.g. in agriculture) \\
Adaptation & - critical infrastructure (water supply) \\
capacity & - Information, Awareness \\
& - Planning processes, co-operation, networking, etc. \\
& - Incentives
\end{tabular}

data layers and their integration using GIS led to vulnerability maps that enable users to get insight into areas that are threatened by harmful phenomena, e.g. flooding, or erosion. RUSLE has not been used so far but is seen as essential in the follow-up project 'BebeR'. Following the elements of Figure 1, and besides the geographic description of the region, the following data are required for the assessment of soil erosion vulnerability (Table 1).

During 'BebeR', the GIS-based intersection of different data layers will be combined with an adapted, model driven simulation approach to improve the identification of vulnerabilities to soil erosion in the areas under investigation. The envisaged methodology uses models to simulate and predict soil erosion (including RUSLE) based on scenarios. It integrates climate data resulting from future predictions (using results from models such as WETTREG, REMO, STAR) as well as data summarized in Table 1. Some insights into components of the methodology are described in [11, 12]; however, an effective integration into a methodological, stepwise and practical approach is foreseen as one achievement in 'BebeR'. The steps that will be carried out to end up with a concrete assessment of soil erosion vulnerability are mentioned below. It is important to note that the inclusion of the relevant actors is vital to achieve sustainable evaluations about the threats. Some components of the methodology to be developed are as follows:

a. Modification of an existing model to calculate the discharge in small rivers, called SMINF, including the RUSLE. For the latter, a GIS-based version is available (called ABAGis, as described by Reinstorf and Köhn [11]).

b. Generation of a sequential model chain (including SMINF and ABAGis) for the analysis and estimation of surface- and river-bed erosion.

c. Parameterization, calibration and validation of the models; sensitivity analysis of the models under usage.

d. Investigation of the erosion behaviour in the test river basins (current situation, current sensitivity).

e. Development of scenarios concerning soils and land use under consideration of climate change (exposure). 
f. Analysis of the erosion behaviour in the test river basins under explicit consideration of climate change predictions; using the adapted soil erosion equations.

g. Simulation of impacts caused by planned adaptation measures (adaptation capacity).

h. Generation of vulnerability maps using GIS, thus representing different possible climate scenarios as well adaptation measures (which result in different soil erosion rates).

A main focus with respect to vulnerability assessment should be brought to the co-operation of the relevant stakeholders to identify a sustainable and economic set of measures particularly concerning the aspects $\mathrm{d}$ to $\mathrm{h}$. By using the same data, it may happen that the assessment of vulnerability and the potential adaptation measures differ. In order to increase the adaptation capacity and the hazard preparedness the usage of vulnerability maps requires training of users. This is another reason for intensive networking cooperation and exchange of experiences.

\section{CASE STUDY FOR SOIL EROSION ASSESSMENT SUPPORTED BY INTERACTIVE VULNERABILITY MAPS AND WEB TOOLS}

\subsection{Description of the model region}

The pilot region for the development of vulnerability assessment tools is the administrative district of Mansfeld-Südharz. This district is situated in the south of the German federal state of Saxony-Anhalt and covers an area of nearly $1450 \mathrm{~km}^{2}$. Land use in the rural areas is dominated by agriculture and forestry.

The administrational authorities of Mansfeld-Südharz have been working on local adaptation measures since 2011. The work was divided into two phases. The goal of the first phase ('Klimpass', 2011-2012) included the compilation of a local adaptation strategy. Within the second project phase ('Klimpass-Aktiv', 2013-2016), the advancement, implementation, and evaluation of specific adaptation measures were envisaged. The development of interactive vulnerability maps and the networking of relevant actors was a key element. Seven fields of action were identified as being of particular importance within the model region:

1. Reduction of soil erosion in agriculturally used areas

2. Change of the management of (small) rivers

3. Concept to dealing with invasive neophytes

4. Adaptation of forest management

5. Improvement of disaster management (especially in conjunction with extreme weather events)

6. Change of administrational methods to include climate change adaptation in urban planning.

7. Adaptation of water provision and wastewater removal.

Soil erosion and the management of small rivers are closely connected. Two river catchments have been selected as exemplary 'pilots' within the 'BebeR' project. The catchment of the 'Regenbeek' represents an area with partly high riverbed erosion, which is caused by strong current after snow melting periods or heavy rainfall. This kind of erosion leads to the destruction of the riverbanks and an unusually deepening of the riverbed. The soil or mud flows to underlying villages or cities pollutes, and potentially destroys, existing infrastructures or 
buildings (Fig. 3). The river 'Vietsbach' instead, represents an area with predominant surface erosion. Heavy rainfall can lead to anomalous bank erosion. This is accompanied by extensive erosion of surrounding arable land.

\subsection{Development of vulnerability maps and the usage of web services}

The participation of relevant actors from different sectors and administrative levels is a prerequisite for a decision making process aimed at the implementation of sustainable adaptation measures.

Therefore, web services or electronic workspaces for networking across governmental and non-governmental bodies, and the public are required, as Brennan et al. mentioned [13]. These tools help to overcome diverse barriers, thus allowing stakeholders to:

- access the information necessary,

- provide their own input and

- engage in a constructive discourse with other actors.

Figure 4 shows the interplay of components that are supported by GIS- and web services within the 'BebeR' project. It includes three main elements: simulation, participation and

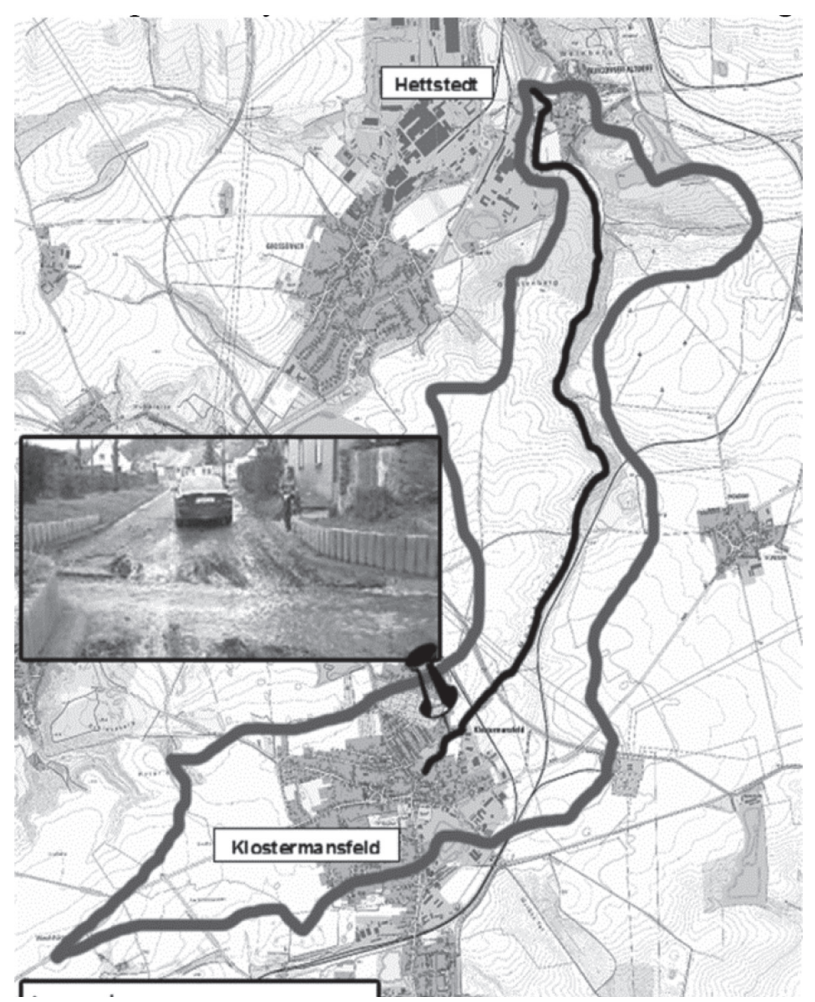

Figure 3: River catchment 'Regenbeek' and hazardous situation caused by erosion. 


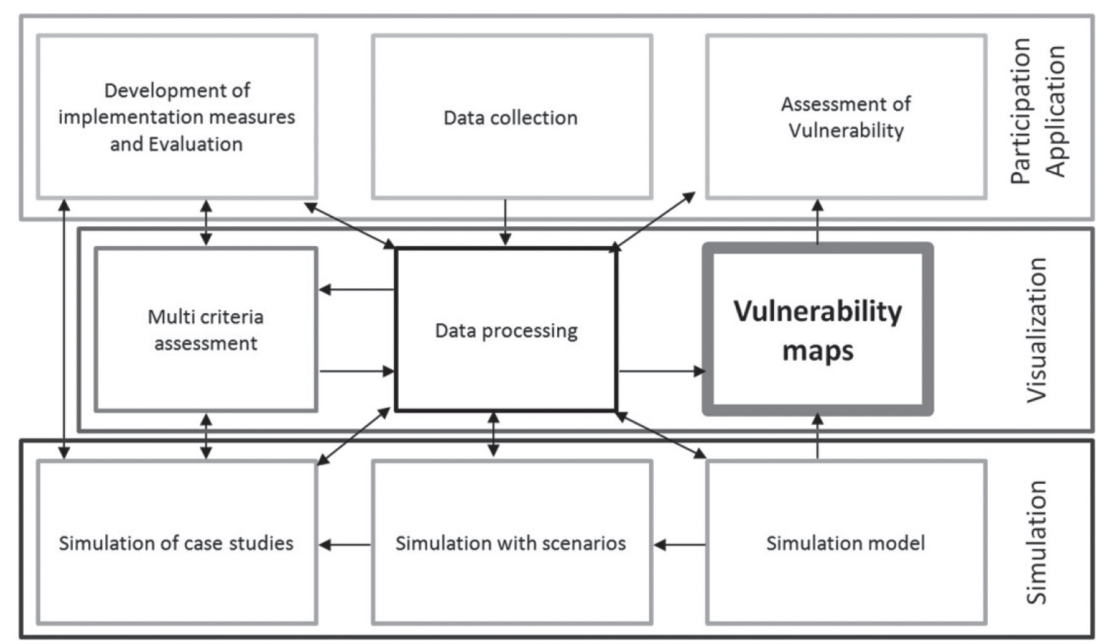

Figure 4: Interplay of components, supported by computer-based GIS- and web-services, as envisaged in the project 'BebeR'.

visualization. The simulation tools will be adapted to the pilot river systems. The goal is to simulate the erosion behavior of the past and calibrate the models based on historical events. Based on this, scenarios will be developed which should help to get insight into potential changes concerning the future erosion behavior under explicit consideration of climate change induced weather events. Scenarios consider different climate projections whereas the simulation of case studies also takes into account possible adaptation measures. Simulation utilizes data that are gathered either from official sources or from stakeholders involved. Besides data collection the web tool should also encourage an open discussion about potential measures as well as about the vulnerability assessment. In such a way, the tool enables active participation of different relevant actors and the proper consideration of their perspectives concerning soil erosion problems.

This methodology promotes a multidisciplinary, cross-sector and transparent approach supported by the mentioned computer tools. Aiming at evaluating and prioritizing adaptation measures the methodology will lead to more comprehensible decisions due to the inclusion of possibly all relevant stakeholders and the improved opportunities for their interaction via web-based services. The decisions will lead presumably to different options envisaging a possibly optimal adaptation to climate change. The occurring alternatives must be prioritized using a transparent methodology. A multi-criteria evaluation of the different outcomes can therefore contribute to a generally accepted prioritization.

The tool 'PRIMATE', a participative and multi-criteria evaluation method, has been used in the foregoing project. It proofed to be suitable for such evaluation purposes. Within the new project, PRIMATE will be used comprehensively and in close cooperation with the actors to achieve results that are accepted by at least most of the included parties [14].

Finally, the documentation is aimed at providing a methodology that can help stakeholders in other regions to act equally or at least similarly. The documentation includes a guide to support the analysis of spatial data layers and the development of vulnerability maps. The latter can be produced by an interactive, GIS-based online mapping system that has been implemented during the pioneer project 'Klimpass-Aktiv'. 


\subsection{Participation of stakeholders and the public}

The actors' involvement in the development of adaptation measures to improve climate change induced hazard preparedness will vary with their roles. These can be distinguished into stakeholders involved (like representatives from authorities, forestry or agriculture) and the public. Stakeholders involved work according to a specific schedule and have designated tasks to fulfill (Fig. 4 - participation/application).

The public should be addressed in order to provide local knowledge, but foremost to increase its awareness. It is possible that important pieces of knowledge can complete the database. It is often the case that local citizens have experiences about facts and processes that can contribute to assess more critically alternative adaptation measures. The involvement of people in scientific and decision-making processes is nowadays often called 'Citizen science', which in such a sense offers great opportunities for climate adaptation [15].

The public should also be included to increase its willingness to implement measures for self-protection (e.g. defense of threats to their estates regarding mud flows from near slopes, or flooding from close rivers).

The online web services support broad participation: users can get insight into the environmental situation of the pilot region; they can also produce maps interactively. Such maps can be published via the project website and be discussed and modified in cooperation with other stakeholders. As an add-on, a discussion forum will be available via which users can critically review planned adaptation measures. The forum is also important to include the public and guarantee more transparency in view of the future scenarios. Citizens can also argue for other or possibly more suitable decisions taking into account that citizens sometimes have important knowledge about local conditions, which are prone to be ignored by administrational units. Apart from the web based participation tools, both stakeholders and the public will be informed using traditional communication instruments like newspapers, workshops and exhibitions.

\section{CONCLUSIONS}

The project 'BebeR', started in January 2017, is based on comprehensive experiences with a cooperative project management approach and online GI-services developed in the foregoing pioneer project 'Klimpass-Aktiv' (2013-2016). During the latter, concrete measures to adapt to climate change were determined and are nowadays under implementation. In 'BebeR', the specific problem of soil erosion is in the focus. The assessment of soil erosion vulnerability requires comprehensive datasets from different sectors, rich expertise from specialists, as well as local knowledge from citizens. Only the proper consideration and integration of data, knowledge and practical experiences will result in adaptation measures that are widely accepted. During this project, running until 2019, a methodology will be developed that enables the development, evaluation and prioritization of measures to mitigate hazardous soil erosion. An online and interactive GIS tool will be used to analyse spatial data and visualize relevant data layers aiming at assessing vulnerabilities and presenting threatened areas. Also, scenarios where and which alternative adaptation measures can be implemented will be presented cartographically using the GI-services. The cooperative weighting of such alternative scenarios including not only the stakeholders, but also the public, will be accompanied by using adequate evaluation methods, supported by an online discussion forum. In such a sense, different computer based tools will be used to enable a participative and cooperative approach: the modeling and simulation program, the GI-services, and the online forum. Vulnerability 
maps, and the forum, will support the critical discussion between project participants, thus envisaging an open dispute about alternative adaptation measures. This contributes to more transparency. The evaluation of adaptation measures will ensure a prioritization that is accepted by most stakeholders. In such a way, the methodology that is envisaged should contribute to minimizing surface and riverbed erosion sustainably or at least to being prepared in case of hazardous events.

\section{REFERENCES}

[1] Sotiropoulou, A.M., Alexandridis, T., Bilas, G., Karapetsas, N., Tzellou, A., Silleos, N. \& Misopolinos, N., A user friendly GIS model for the estimation of erosion risk in agricultural land using the USLE. In: Proceeding of the International Conference on Information and Communication Technologies for Sustainable Agri-production and Environment, eds M. Salampasis \& A. Matopoulos, pp. 795-801, 2011.

[2] Wegehenkel, M., Heinrich, U., Jochheim, H., Kersebaum K.C. \& Röber, K., Evaluation of three different regional climate change scenarios for the application of a water balance model in a mesoscale catchment in Northeast Germany. Advances in Geosciences, 27, pp. 57-64, 2010. https://doi.org/10.5194/adgeo-27-57-2010

[3] Schmidt, C., Klimaanpassung auf Regionaler Ebene am Beispiel der Region Westsachsen und Oberlausitz-Niederschlesien. In: Lehr- und Forschungsgebiet Landschaftsplanung der Techn. Univ. Dresden eds, Klimaanpassungsstrategien in der Landschaftsund Raumplanung, Band 2.

[4] NSERL (National Soil Erosion Laboratory, Purdue University Indiana), 2017. Revised Universal Soil Loss Equation, Version 2 (RUSLE2), available at: http://fargo.nserl.purdue.edu/rusle2_dataweb/RUSLE2_Index.htm (accessed 23 January 2017).

[5] Beskow, S., Mello, C.R. \& Norton, L.D., Soil erosion prediction in the Grande River Basin, Brazil using distributed modeling. CATENA, 79(1), pp. 49-59, 2009. https://doi.org/10.1016/j.catena.2009.05.010

[6] Biswas, H., Raizada1, A., Mandal, D., Kumar, S., Srinivas, S. \& Mishra, P.K., Identification of areas vulnerable to soil erosion risk in India using GIS methods. Solid Earth, 6(4), 1247-1257, 2015. https://doi.org/10.5194/se-6-1247-2015

[7] Durães, M.F. \& Mello, C.R., Groundwater recharge behavior based on surface runoff hydrographs in two basins of the Minas Gerais State. Revista Ambiente \& Água, 8(2), pp. 1-10, 2013. https://doi.org/10.4136/ambi-agua.1127

[8] Mello, C.R., Viola, M.R., Beskow, S. \& Norton, L.D., Multivariate models for annual rainfall erosivity in Brazil. Geoderma, 202-203, pp. 88-102, 2013.

https://doi.org/10.1016/j.geoderma.2013.03.009

[9] Routschek, A., Auswirkungen des Klimawandels auf die Bodenerosion durch Wasser, Schriftenreihe des LfULG, Heft 29.

[10] Pradhan, B., Chaudhari, A., Adinarayana, J. \& Buchroithner, M.F., Soil erosion assessment and its correlation with landslide events using remote sensing data and GIS: a case study at Penang Island, Malaysia. Environmental Monitoring and Assessment, 184(2), pp. 715-727, 2012.

https://doi.org/10.1007/s10661-011-1996-8 
[11] Reinstorf, F. \& Köhn, J., Ursachenermittlung und Maßnahmenplanung zur Vermeidung von Bodenerosion im Einzugsgebiet des Regenbeeks, Landkreis Mansfeld-Südharz, Project Report, Univ. Appl. Sciences Magdeburg-Stendal, 2015.

[12] Scheinert, M., Pundt, H. \& Heilmann, A., Climate change adaptation and interactive participation of stakeholders - first Results of the Project "KLIMPASS-AKTIV". In: J. Marx Gómez, M. Sonnenschein, U. Vogel, A. Winter, B. Rapp \& N. Giesen, eds. EnviroInfo 2014, 28th Internatonal Conference on Informatics for Environmental Protection. BIS-Verlag, Oldenburg, pp. 181-188, 2014.

[13] Brennan, J., Heilmann, A. \& Pundt, H., An information systems approach to developing adaptation strategies. Proceeding of the European, Mediterranean \& Middle Eastern Conference on Information Systems 2012, EMCIS2012, Munich, Germany, pp. 231-241, 2012.

[14] Scheuer, S., Haase, D. \& Meyer, V., Exploring multicriteria flood vulnerability by integrating economic, social and ecological dimensions of flood risk and coping capacity from a starting point view towards an end point view of vulnerability. Natural Hazards, 58(2), pp. 731-751.

https://doi.org/10.1007/s11069-010-9666-7

[15] Available at: www.buergerschaffenwissen.de: Green Paper Citizen Science Strategy 2020 for Germany, 2016. 